Virginia Commonwealth University VCU Scholars Compass behavioral-analysis system of psychotherapy, and their combination for the treatment of chronic depression

\author{
Martin B. Keller, M.D. \\ Brown University \\ James P. McCullough, Ph.D. \\ Virginia Commonwealth University, The Unipolar Mood Disorders Institute \\ Daniel N. Klein, Ph.D. \\ State University of New York at Stony Brook \\ See next page for additional authors
}

Follow this and additional works at: http://scholarscompass.vcu.edu/psyc_pubs

\title{
Part of the Psychology Commons
}

From The New England Journal of Medicine, Keller, M.B., McCullough, J.P., Klein, D.N., et al., A comparison of nefazodone, the cognitive behavioral-analysis system of psychotherapy, and their combination for the treatment of chronic depression, Vol. 342, Page 1462, Copyright (C 2000 Massachusetts Medical Society. Reprinted with permission.

\section{Downloaded from}

http://scholarscompass.vcu.edu/psyc_pubs/29

This Article is brought to you for free and open access by the Dept. of Psychology at VCU Scholars Compass. It has been accepted for inclusion in Psychology Publications by an authorized administrator of VCU Scholars Compass. For more information, please contact libcompass@vcu.edu. 


\section{Authors}

Martin B. Keller , M.D.; James P. McCullough , Ph.D.; Daniel N. Klein , Ph.D.; Bruce Arnow , Ph.D.; David L. Dunner, M.D.; Alan J. Gelenberg, M.D.; John C. Markowitz, M.D.; Charles B. Nemeroff, M.D., Ph.D.; James M. Russell M.D.; Michael E. Thase , M.D.; Madhukar H. Trivedi , M.D.; Janice A. Blalock , Ph.D.; Frances E. Borian, R.N.; Darlene N. Jody, M.D.; Charles DeBattista , D.M.H., M.D.; Lorrin M. Koran, M.D.; Alan F. Schatzberg, M.D.; Jan Fawcett , M.D.; Robert M.A. Hirschfeld , M.D.; Gabor Keitner , M.D.; Ivan Miller , Ph.D.; James H. Kocsis , M.D.; Susan G. Kornstein , M.D.; Rachel Manber , Ph.D.; Philip T. Ninan , M.D.; Barbara Rothbaum, Ph.D.; A. John Rush , M.D.; Dina Vivian, Ph.D.; and John Zajecka , M.D. 


\title{
The New England Journal of Medicine
}

(C) Copyright, 2000 , by the Massachusetts Medical Society

VOLUME 342

MAY 18, 2000

NUMBER 20

\section{A COMPARISON OF NEFAZODONE, THE COGNITIVE BEHAVIORAL-ANALYSIS SYSTEM OF PSYCHOTHERAPY, AND THEIR COMBINATION FOR THE TREATMENT OF CHRONIC DEPRESSION}

\author{
Martin B. Keller, M.D., James P. McCullough, Ph.D., Daniel N. Klein, Ph.D., Bruce Arnow, Ph.D., \\ David L. Dunner, M.D., Alan J. Gelenberg, M.D., John C. Markowitz, M.D., Charles B. Nemeroff, M.D., Ph.D., \\ James M. Russell, M.D., Michael E. Thase, M.D., Madhukar H. Trivedi, M.D., and John ZajeCKA, M.D.
}

\section{AbStRACT}

Background Patients with chronic forms of major depression are difficult to treat, and the relative efficacy of medications and psychotherapy is uncertain.

Methods We randomly assigned 681 adults with a chronic nonpsychotic major depressive disorder to 12 weeks of outpatient treatment with nefazodone (maximal dose, $600 \mathrm{mg}$ per day), the cognitive behavioral-analysis system of psychotherapy (16 to 20 sessions), or both. At base line, all patients had scores of at least 20 on the 24-item Hamilton Rating Scale for Depression (indicating clinically significant depression). Remission was defined as a score of 8 or less at weeks 10 and 12. For patients who did not have remission, a satisfactory response was defined as a reduction in the score by at least 50 percent from base line and a score of 15 or less. Raters were unaware of the patients' treatment assignments.

Results Of the 681 patients, 662 attended at least one treatment session and were included in the analysis of response. The overall rate of response (both remission and satisfactory response) was 48 percent in both the nefazodone group and the psychotherapy group, as compared with 73 percent in the combinedtreatment group ( $\mathrm{P}<0.001$ for both comparisons). Among the 519 subjects who completed the study, the rates of response were 55 percent in the nefazodone group and 52 percent in the psychotherapy group, as compared with 85 percent in the combined-treatment group ( $P<0.001$ for both comparisons). The rates of withdrawal were similar in the three groups. Adverse events in the nefazodone group were consistent with the known side effects of the drug (e.g., headache, somnolence, dry mouth, nausea, and dizziness).

Conclusions Although about half of patients with chronic forms of major depression have a response to short-term treatment with either nefazodone or a cognitive behavioral-analysis system of psychotherapy, the combination of the two is significantly more efficacious than either treatment alone. (N Engl J Med 2000;342:1462-70.)

(C)2000, Massachusetts Medical Society. $\longrightarrow$ RADITIONALLY thought of as an episodic, remitting illness, major depressive disorder often has a chronic course, with protracted episodes or incomplete remission between episodes. ${ }^{1-3}$ At any given time, at least 3 percent of the U.S. population suffers from chronic depression. 4,5 Chronic forms of major depression are associated with more marked impairments in psychosocial function and work performance, ${ }^{6-8}$ increased health care utilization, 5,9 and more frequent suicide attempts and hospitalization ${ }^{10}$ than acute depression.

From the Department of Psychiatry, Brown University, Providence, R.I. (M.B.K.); the Unipolar Mood Disorders Institute, Department of Psychology, Virginia Commonwealth University, Richmond (J.P.M.); the Department of Psychology, State University of New York at Stony Brook, Stony Brook (D.N.K.); the Department of Psychiatry and Behavioral Sciences, Stanford University, Stanford, Calif. (B.A.); the Department of Psychiatry and Behavioral Sciences, University of Washington, Seattle (D.L.D.); the Department of Psychiatry, University of Arizona, Tucson (A.J.G.); the Department of Psychiatry, Cornell University Medical College, New York (J.C.M.); the Department of Psychiatry, Emory University School of Medicine, Atlanta (C.B.N.); the Department of Psychiatry and Behavioral Sciences, University of Texas Medical Branch at Galveston, Galveston (J.M.R.); the Department of Psychiatry, Western Psychiatric Institute and Clinic, University of Pittsburgh, Pittsburgh (M.E.T.); the Department of Psychiatry, University of Texas Southwestern Medical Center at Dallas, Dallas (M.H.T.); and the Department of Psychiatry, Rush-Presbyterian-St. Luke's Medical Center, Chicago (J.Z.). Address reprint requests to Dr. Keller at the Department of Psychiatry and Human Behavior, Brown University, 345 Blackstone Blvd., Providence, RI 02906.

Other authors were Janice A. Blalock, Ph.D. (M.D. Anderson Cancer Center, Houston); Frances E. Borian, R.N., and Darlene N. Jody, M.D. (Bristol-Myers Squibb, Plainsboro, N.J.); Charles DeBattista, D.M.H., M.D., Lorrin M. Koran, M.D., and Alan F. Schatzberg, M.D. (Stanford University, Stanford, Calif.); Jan Fawcett, M.D. (Rush-Presbyterian-St. Luke's Medical Center, Chicago); Robert M.A. Hirschfeld, M.D. (University of Texas Medical Branch at Galveston, Galveston); Gabor Keitner, M.D., and Ivan Miller, Ph.D. (Brown University, Providence); James H. Kocsis, M.D. (Cornell University Medical College, New York); Susan G. Kornstein, M.D. (Virginia Commonwealth University, Richmond); Rachel Manber, Ph.D. (University of Arizona, Tucson); Philip T. Ninan, M.D., and Barbara Rothbaum, Ph.D. (Emory University School of Medicine, Atlanta); A. John Rush, M.D. (University of Texas Southwestern Medical Center at Dallas, Dallas); and Dina Vivian, Ph.D. (State University of New York at Stony Brook, Stony Brook). 
Because they frequently begin early in life ${ }^{11}$ and are often lifelong, chronic forms of major depression account for an inordinate proportion of the enormous burden of illness associated with depression..$^{12}$

Several studies have demonstrated the efficacy of antidepressants as both initial ${ }^{13-16}$ and maintenance ${ }^{17,18}$ treatment for chronic forms of major depression, but controlled clinical trials of sufficient size to examine the efficacy of psychotherapy in chronic forms of major depression are lacking. ${ }^{19}$ The combination of pharmacotherapy and psychotherapy has been recommended as the treatment of choice for depression by practice guidelines for psychiatrists ${ }^{20}$ and as the treatment of choice for chronic forms of major depression in primary care practice. ${ }^{21}$ However, the results of studies investigating whether combination treatment is superior to single treatments have been inconclusive. $22-24$

We present the main findings from the initial (12week) phase of a long-term multicenter study comparing nefazodone alone, the cognitive behavioralanalysis system of psychotherapy alone, ${ }^{25,26}$ or the two in combination with regard to efficacy in the treatment of patients with chronic forms of major depression. Nefazodone has had demonstrated efficacy in placebo-controlled trials and in numerous double-blind trials of short-term treatment of major depressive disorders, ${ }^{27}$ as well as a demonstrated ability to prevent relapse after such treatment. ${ }^{28}$

The cognitive behavioral-analysis system of psychotherapy was developed specifically for the treatment of chronic forms of major depression and produced promising results in a small, open trial. ${ }^{29}$ This approach draws on many behavioral, cognitive, and interpersonal techniques used in other forms of psychotherapy. ${ }^{30-32}$ It teaches patients to focus on the consequences of their behavior and to use a social problem-solving algorithm to address interpersonal difficulties. It is more structured and directive than interpersonal psychotherapy ${ }^{30}$ and differs from cognitive therapy ${ }^{31}$ by focusing primarily on interpersonal interactions (including those with therapists). In this type of psychotherapy, patients learn how their cognitive and behavioral patterns produce and perpetuate their interpersonal problems and learn how to remedy maladaptive patterns of interpersonal behavior.

\section{METHODS}

\section{Patients}

We studied outpatients, recruited from 12 academic centers between June 1996 and December 1997, who fulfilled the criteria for a chronic major depressive disorder (at least two years' duration), a current major depressive disorder superimposed on a preexisting dysthymic disorder, or a recurrent major depressive disorder with incomplete remission between episodes in a patient with a current major depressive disorder and a total duration of continuous illness of at least two years. Diagnoses were based on the Diagnostic and Statistical Manual of Mental Disorders, fourth edition (DSM-IV), ${ }^{33}$ and were obtained with use of the Structured Clinical Interview for Axis I DSM-IV Disorders. ${ }^{34}$

To be eligible for the study, the patients had to be between the ages of 18 and 75 years and to have had a score of at least 20 on the 24-item Hamilton Rating Scale for Depression (HRSD) ${ }^{35}$ at screening and, after a two-week drug-free period, at base line. On this scale, higher scores indicate more severe depression. Laboratory tests, electrocardiography (if clinically indicated), and physical examinations were performed at the time of screening. Patients were required to discontinue taking monoamine oxidase inhibitors and fluoxetine at least four weeks before study entry, depot neuroleptic agents at least six months before entry, and other psychotropic medications at least two weeks before entry.

Patients were excluded from the study if they had any of the following: a history of seizures, abnormal findings on electroencephalography, severe head trauma, or stroke; evidence suggesting they were at high risk for suicide; a history of psychotic symptoms or schizophrenia; bipolar disorder, an eating disorder (if it had not been in remission for at least one year), obsessive-compulsive disorder, or dementia; antisocial, schizotypal, or severe borderline personality disorder; a principal diagnosis of panic, generalized anxiety, social phobia, or post-traumatic stress disorders or any substance-related abuse or dependence disorder (except those involving nicotine) within six months before the study began; absence of a response to a previous adequate trial of nefazodone or a cognitive behavioral-analysis system of psychotherapy; absence of a response to three previous adequate trials of at least two different classes of antidepressants or electroconvulsive therapy or to two previous adequate trials of empirical psychotherapy in the three years preceding the study; a serious, unstable medical condition; or a positive urine screen for drugs of abuse. Women of childbearing potential had to agree to use adequate contraception during the study. Patients were not allowed to take anxiolytic agents, sedatives, hypnotic agents, or any other types of sleep aids (pharmacologic or behavioral) during the study.

\section{Study Design}

The institutional review board at each center approved the study. All patients provided written informed consent. Patients who remained eligible at the end of the two-week evaluation period were randomly assigned, according to a central computerized randomization schedule, in a 1:1:1 ratio to receive nefazodone (Serzone, Bristol-Myers Squibb), psychotherapy, or a combination of nefazodone and psychotherapy. The Structured Clinical Interview for Axis I DSM-IV Disorders and the HRSD were administered by experienced clinical raters (study coordinators) certified to have a high rate of interrater reliability and level of procedural integrity. Each site implemented procedures to mask the patient's treatment assignment from the person who evaluated the results of the HRSD, and the degree of adherence to these procedures was monitored at each study visit. At all sites the rater was located at a separate physical location so that he or she could not see patients arriving for or departing from treatment sessions.

Among the patients who received nefazodone, the initial dose was $200 \mathrm{mg}$ per day (100 $\mathrm{mg}$ twice a day) and was increased to $300 \mathrm{mg}$ per day during the second week. Thereafter, the dose was increased weekly in increments of $100 \mathrm{mg}$ per day to a maximum of $600 \mathrm{mg}$ per day, to maximize the efficacy of the drug without producing intolerable side effects. To remain in the study, patients had to be receiving a dose of at least $300 \mathrm{mg}$ per day by week 3 .

Visits for medication were limited to 15 to 20 minutes. Psychopharmacologists followed a published manual ${ }^{36}$ for clinical management (e.g., patients were questioned about the concomitant use of medications and symptoms, side effects, and illnesses they had had between visits). The psychopharmacologists were not allowed to make formal psychotherapeutic interventions (such as suggesting ways to cope with stressful life events).

The cognitive behavioral-analysis system of psychotherapy also followed a manual ${ }^{37}$ specifying twice-weekly sessions during weeks 1 through 4 and weekly sessions during weeks 5 through 12 . Twice- 
weekly sessions could be extended until week 8 if a patient was not adequately performing a learned social problem-solving procedure according to the criteria.

Psychotherapists (persons who had at least two years' experience after earning an M.D. or Ph.D. or at least five years' experience after earning an M.S.W.) attended a two-day training workshop and met the criteria for mastery of treatment procedures involved in the cognitive behavioral-analysis system of psychotherapy, as assessed by evaluation of their performance during two videotaped pilot cases. All psychotherapy sessions conducted during the study were videotaped, and supervisors reviewed the videotapes weekly to assess the psychotherapists' adherence to the treatment procedures.

\section{Outcome Measures}

The score on the 24-item HRSD was the primary outcome. The Global Assessment of Functioning Scale (Axis V in the DSMIV) was administered at base line, and the results were evaluated by the same person who evaluated the HRSD results. Remission was defined a priori as an HRSD score of no more than 8 at both week 10 and week 12 for those who completed the 12 -week protocol and at the time of withdrawal for those who did not complete the study. A satisfactory therapeutic response was defined as a reduction in the HRSD score by at least 50 percent from base line to week 10 and week 12 , with a total score of 15 or less at these times but of more than 8 at week 10 , week 12 , or both for those who completed the study and at the time of departure for those who did not complete the study. The patients with these favorable outcomes were combined to form a single response group. All other patients were considered to have had no response.

\section{Statistical Analysis}

The base-line demographic and clinical characteristics of the treatment groups were compared with the use of analysis of variance for continuous variables and the Cochran-Mantel-Haenszel test for categorical variables, with site as the stratification variable. Preliminary paired t-tests were conducted separately for each treatment group to examine the significance of the changes in the HRSD scores from base line to the end point.

No outcome data were collected on patients who withdrew from the study after they withdrew, and a formal intention-to-treat analysis thus could not be performed. The primary analysis was a modified intention-to-treat analysis that included all patients who attended at least one treatment visit and who had at least one assessment after the base-line evaluation. Patients who underwent randomization but who did not return for a subsequent assessment were therefore not included in this analysis. Given this modified approach, the main efficacy analysis was a piecewise mixedeffects linear model that examined the relative differences between treatments with respect to the rate of change in the HRSD score (the linear slope) from base line to week 4 as one variable and from week 4 to week 12 (or the last visit) as a second variable. The a priori rationale for examining the first four weeks separately was that the earliest antidepressant effects of nefazodone are likely to occur at week 4 if a stable dosage has been achieved. Each model estimated fixed effects with respect to treatment and site, as well as the interactions between treatment and time. In addition, the models included a random intercept and a random slope. Interactions between treatment and site were not significant and therefore were not included in the models. The statistical significance of additional terms included in successive models was determined by the likelihood-ratio test. The error structure was specified as nonstationary autocorrelation in each model. There were no interim analyses of the data.

In addition to the mixed-model analysis, we examined response and remission rates that were based on the total HRSD score. We used the Cochran-Mantel-Haenszel test to analyze these rates in the modified intention-to-treat sample and among the patients who completed the study (with site as the stratification variable). We also performed an analysis of covariance of the change in total
Table 1. Status of the 681 Patients During the 12 -Week Study, According to the Treatment Assignment.

\begin{tabular}{|c|c|c|c|}
\hline \multirow[t]{2}{*}{ Status } & $\begin{array}{l}\text { NefAZODONE } \\
(\mathrm{N}=226)\end{array}$ & $\begin{array}{l}\text { PsYCHOTHERAPY } \\
\text { (N=228) }\end{array}$ & $\begin{array}{l}\text { NEFAZODONE AND } \\
\text { PsYCHOTHERAPY } \\
\text { (N=227) }\end{array}$ \\
\hline & \multicolumn{3}{|c|}{ number (percent) } \\
\hline $\begin{array}{l}\text { Included in modified inten- } \\
\text { tion-to-treat sample* }\end{array}$ & $-220(97)$ & $216(95)$ & $226(>99)$ \\
\hline Completed the study & $167(74)$ & $173(76)$ & $179(79)$ \\
\hline Withdrew from the study & $59(26)$ & $55(24)$ & $48(21)$ \\
\hline Lack of efficacy & $2(1)$ & $3(1)$ & $3(1)$ \\
\hline Adverse events & $31(14)$ & $3(1)$ & $16(7)$ \\
\hline Withdrew consent & $11(5)$ & $32(14)$ & $17(7)$ \\
\hline Protocol violation & $2(1)$ & $2(1)$ & 0 \\
\hline Lost to follow-up & $7(3)$ & 0 & $1(<1)$ \\
\hline Other reasons & $6(3)$ & $15(7)$ & $11(5)$ \\
\hline
\end{tabular}

*The modified intention-to-treat sample consisted of all randomized patients who attended at least one treatment visit and who had at least one efficacy assessment after the base-line evaluation.

HRSD scores from base line to the end point, with base-line scores as the covariate, on these two samples. The model included treatment and site as the main effects. The interactions between treatment and site were again not significant and, hence, were not included in the model. We made pairwise comparisons of the means of the three treatment groups (adjusted for base-line values) using simple contrasts. Overall differences between treatments were evaluated with use of an alpha level of 0.05 , whereas pairwise comparisons used an alpha level of $0.0167(0.05 \div 3)$ with Bonferroni's correction.

We used Fisher's exact test to analyze the incidence of adverse events and rate of discontinuation of treatment in the three groups. All statistical tests were two-tailed. The data analysis was done by a biostatistical data-management company (Statprobe, Ann Arbor, Mich.), according to a plan devised by the authors. The company was selected and paid by Bristol-Myers Squibb.

\section{RESULTS}

\section{Base-Line Clinical and Demographic Characteristics}

A total of 1035 patients were screened for the study. Of the 354 who did not undergo randomization, 235 (66 percent) did not meet the study criteria, 47 (13 percent) withdrew their consent, and 72 (20 percent) were excluded for other reasons (e.g., failure to return for further evaluation or noncompliance). A total of 681 patients underwent randomization: 226 were assigned to receive nefazodone, 228 to receive psychotherapy, and 227 to receive combined treatment (Table 1). Randomization was not stratified according to site. At each site, approximately equal numbers of patients underwent randomization to the three groups. However, there were no significant differences among the groups with respect to base-line demographic and clinical characteristics (Table 2), either among the sites overall or within sites.

\section{Treatment}

For the modified intention-to-treat sample, the mean $( \pm S D)$ final daily dose of nefazodone was $466 \pm$ 
Table 2. Base-Line Characteristics of the Patients.*

\begin{tabular}{|c|c|c|c|c|}
\hline ChaRACteristic & $\begin{array}{l}\text { Nefazodone } \\
(\mathrm{N}=\mathbf{2 2 6})\end{array}$ & $\begin{array}{l}\text { PSYCHOTHERAPY } \\
\text { (N=228) }\end{array}$ & $\begin{array}{l}\text { NEFAZODONE AND } \\
\text { PSYCHOTHERAPY } \\
(\mathbf{N}=\mathbf{2 2 7})\end{array}$ & $\begin{array}{l}\text { ALL PATIENTS } \\
(\mathrm{N}=681)\end{array}$ \\
\hline Female sex $(\%)$ & 64.2 & 62.7 & 69.2 & 65.3 \\
\hline Age $(\mathrm{yr})$ & $42.2 \pm 11.0$ & $43.2 \pm 10.8$ & $44.4 \pm 10.3$ & $43 \pm 10.7$ \\
\hline White race $(\%)$ & 87.2 & 91.7 & 92.5 & 90.5 \\
\hline $\begin{array}{l}\text { Marital status (\%) } \\
\text { Married or cohabiting } \\
\text { Single } \\
\text { Widowed } \\
\text { Divorced or separated }\end{array}$ & $\begin{array}{r}42.9 \\
27.4 \\
2.7 \\
27.0\end{array}$ & $\begin{array}{r}41.6 \\
30.3 \\
1.3 \\
26.8\end{array}$ & $\begin{array}{r}43.6 \\
23.8 \\
2.2 \\
30.4\end{array}$ & $\begin{array}{r}42.7 \\
27.2 \\
2.1 \\
28.0\end{array}$ \\
\hline $\begin{array}{l}\text { Depression diagnosis (\%) } \\
\text { Chronic major depression } \\
\text { MDD with dysthymic disorder } \\
\text { Recurrent depression, with incomplete remission } \\
\text { between episodes }\end{array}$ & $\begin{array}{l}36.7 \\
42.9 \\
20.4\end{array}$ & $\begin{array}{l}35.5 \\
39.9 \\
24.6\end{array}$ & $\begin{array}{l}33.0 \\
44.1 \\
22.9\end{array}$ & $\begin{array}{l}35.1 \\
42.3 \\
22.6\end{array}$ \\
\hline Age at onset of MDD (yr) & $25.6 \pm 13$ & $27.5 \pm 13$ & $27.1 \pm 13$ & $26.7 \pm 13$ \\
\hline Age at onset of dysthymia $(\mathrm{yr})$ & $17.8 \pm 13$ & $19.7 \pm 14$ & $20.3 \pm 14$ & $19.3 \pm 14$ \\
\hline Duration of current episode of MDD (yr) & $7.5 \pm 9$ & $7.8 \pm 10$ & $8.0 \pm 9.5$ & $7.8 \pm 9.6$ \\
\hline Duration of current episode of dysthymia (yr) & $22.3 \pm 15$ & $22.5 \pm 15$ & $24.2 \pm 16$ & $23.0 \pm 15$ \\
\hline History of anxiety disorder (\%) & 33.6 & 28.5 & 36.1 & 32.7 \\
\hline Diagnosis of coexisting personality disorder (\%) & 59.3 & 53.9 & 63.0 & 58.7 \\
\hline History of alcohol- or substance-abuse disorder (\%) & 34.5 & 33.3 & 31.7 & 33.2 \\
\hline Prior treatment with antidepressants (\%) & 57.5 & 59.5 & 63.6 & 60.2 \\
\hline Prior psychotherapy (\%) & 65.9 & 61.2 & 68.4 & 65.2 \\
\hline $\begin{array}{l}\text { Prior treatment with both antidepressants and } \\
\text { psychotherapy (\%) }\end{array}$ & 43.4 & 42.3 & 49.6 & 45.1 \\
\hline No prior treatment for depression (\%) & 19.9 & 22.0 & 17.1 & 19.7 \\
\hline Global Assessment of Functioning score $†$ & $53.8 \pm 5.4$ & $53.9 \pm 5.7$ & $53.6 \pm 5.6$ & $54.0 \pm 5.6$ \\
\hline
\end{tabular}

*Plus-minus values are means \pm SD. MDD denotes major depressive disorder.

†The score on the Global Assessment of Functioning Scale, which assesses the overall severity of psychiatric symptoms and functional impairment, can range from 1 to 100 . Scores ranging from 1 to 20 indicate a patient who is a danger to others or to himself or herself. Scores ranging from 21 to 40 indicate a patient with moderate-to-severe impairments who should be hospitalized. Scores ranging from 41 to 60 indicate a patient with serious, nonpsychotic symptoms that impair function. Scores ranging from 61 to 80 indicate a patient with mild or transient symptoms who may require occasional counseling and psychotherapy. Scores ranging from 81 to 100 indicate a person with good functioning who does not require counseling.

$144 \mathrm{mg}$ in the nefazodone group (data available for 216 patients) and $460 \pm 139 \mathrm{mg}$ in the combinedtreatment group (221 patients). Among the patients who completed the study and for whom data on dose were available, the mean final daily dose of nefazodone was $520 \pm 100 \mathrm{mg}$ among 92 patients with a response in the nefazodone group and $479 \pm 111 \mathrm{mg}$ among the 152 patients with a response in the combined-treatment group. The dose was $491 \pm 125 \mathrm{mg}$ among 73 patients without a response in the nefazodone group and $539 \pm 96 \mathrm{mg}$ among the 27 patients without a response in the combined-treatment group.

For the modified intention-to-treat sample, the average number of psychotherapy sessions was 16.0 \pm 4.7 among 216 patients in the psychotherapy group and 16.2 \pm 4.8 among 226 patients in the combinedtreatment group. Among those who completed the study, the 90 patients with a response in the psychotherapy group and the 152 such patients in the combined-treatment group attended a mean of 18.2 \pm 1.9 sessions, whereas the number was $17.7 \pm 1.9$ among the 83 patients in the psychotherapy group who had no response and $17.9 \pm 1.4$ among the 27 patients in the combined-treatment group who had no response.

\section{Efficacy}

Analyses revealed a significant improvement within patients in the HRSD scores from base line to week 12 in the group of patients who completed the study $(\mathrm{P}<0.001)$ and from base line to the last follow-up visit in the modified intention-to-treat sample $(\mathrm{P}<0.001)$ in all three groups. The mixed-effects piecewise linear regression examining the course of the scores during the 12 weeks of the trial (Fig. 1) showed that from base line through week 4 , the average rate of improvement in the scores for patients in the combined-treatment group was not significantly different from the average rate of improvement in the scores for patients in the nefazodone group $(\mathrm{P}=$ $0.39)$. However, the results of the analysis of the rate 


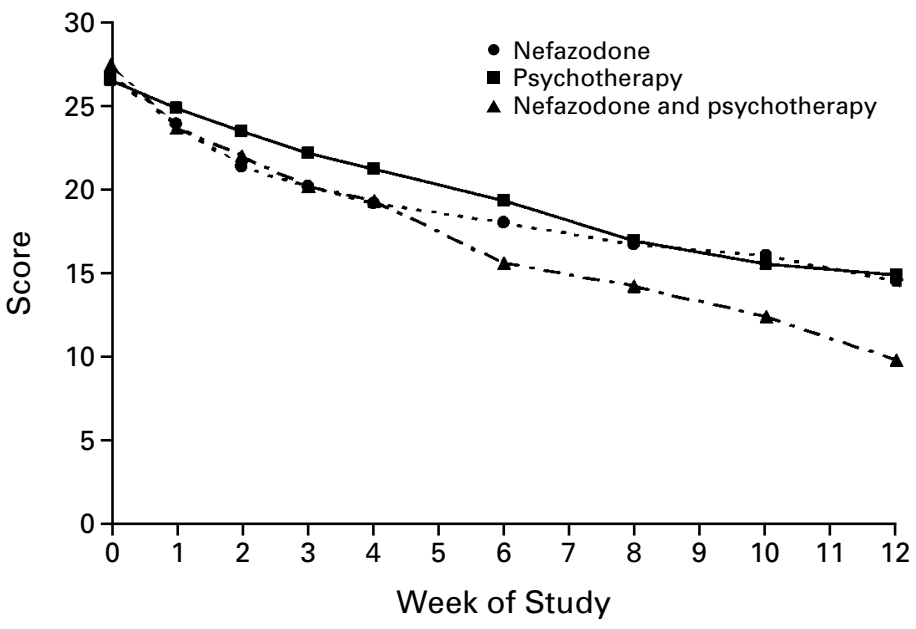

NO. OF PATIENTS

$\begin{array}{llllllllll}\text { Nefazodone } & 220 & 202 & 195 & 194 & 188 & 181 & 164 & 160 & 153 \\ \text { Psychotherapy } & 216 & 180 & 190 & 185 & 190 & 174 & 168 & 166 & 156 \\ \text { Nefazodone and } & 226 & 210 & 212 & 206 & 201 & 197 & 184 & 182 & 173\end{array}$

Figure 1. Mean Scores on the Hamilton Rating Scale for Depression during the 12-Week Study.

The results of the analysis of the rate of improvement in the scores as a regression slope were as follows: for base line through week 4, $\mathrm{P}<0.001$ for the comparison of combined treatment and psychotherapy, $\mathrm{P}=0.004$ for the comparison of nefazodone and psychotherapy, and $\mathrm{P}=0.39$ for the comparison of combined treatment and nefazodone; and for weeks 4 through $12, \mathrm{P}<0.001$ for the comparison of combined treatment and nefazodone and of psychotherapy and nefazodone and $P=0.06$ for the comparison of combined treatment and psychotherapy.

Table 3. Rates of Response and Remission.*

Group

Nefazodone Psychotherapy

Nefazodone AND
PSYCHOTHERAPY

\section{P VALUe}

NEFAZODONE VS. PSYCHOTHERAPY VS. COMBINED COMBINED PSYCHOTHERAPY TREATMENT TREATMENT

no. of patients (\%)

Modified intention-to-treat sample

No. of patients

Response

Remission

Satisfactory response

No response

Patients who completed the study

No. of patients

Response

Remission

Satisfactory response

No response

\begin{tabular}{rrr}
220 & 216 & \multicolumn{1}{l}{226} \\
$105(48)$ & $103(48)$ & $165(73)$ \\
$64(29)$ & $72(33)$ & $109(48)$ \\
$41(19)$ & $31(14)$ & $56(25)$ \\
$113(51)$ & $113(52)$ & $57(25)$ \\
& & \\
167 & 173 & 179 \\
$92(55)$ & $90(52)$ & $152(85)$ \\
$36(22)$ & $41(24)$ & $75(42)$ \\
$56(34)$ & $49(28)$ & $77(43)$ \\
$73(44)$ & $83(48)$ & $27(15)$
\end{tabular}

0.92

0.37

0.21

$<0.001$

$<0.001$

$<0.001$

$<0.001$

0.004

0.57

0.64

0.30
$<0.001$

$<0.001$

*The responses of two patients in the nefazodone group who completed the study could not be determined because no scores were available for the Hamilton Rating Scale for Depression at week 10 or 12. In the modified intention-to-treat sample, no post-randomization scores were available for two patients in the nefazodone group and four in the combined-treatment group. Remission was defined as a score of no more than 8 at both week 10 and week 12 for those who completed the 12 -week protocol and when they left the trial for those who did not complete the study. A satisfactory response was defined as a reduction in the score by at least 50 percent from base line to week 10 and week

12, with a total score of 15 or less at these times but of more than 8 at week 10, week 12, or both for those who completed the study and at the time of departure for those who did not complete the study. 
of improvement in the scores as a regression slope showed significant differences between the nefazodone group and the psychotherapy group $(\mathrm{P}=0.004)$ and between the combined-treatment group and the psychotherapy group $(\mathrm{P}<0.001)$. From week 4 through week 12 , the average rate of improvement in the HRSD scores for patients in the combined-treatment group was significantly larger than the rate of improvement in scores for patients in the nefazodone group $(\mathrm{P}<0.001)$. There was also a significant difference in the rate of improvement in scores between the psychotherapy group and the nefazodone group $(\mathrm{P}<0.001)$ but not between the combined-treatment group and the psychotherapy group $(\mathrm{P}=0.06)$.

The overall rate of response was significantly higher in the combined-treatment group than in the nefazodone group or the psychotherapy group in both the modified intention-to-treat sample and the group of patients who completed the study $(\mathrm{P}<0.001$ for all comparisons) (Table 3 ). For the modified intention-to-treat sample, the overall rates of response were 48 percent in the psychotherapy group ( 95 percent confidence interval, 41.5 to 54.8 percent), 48 percent in the nefazodone group (95 percent confidence interval, 41.0 to 54.3 percent), and 73 percent in the combined-treatment group (95 percent confidence interval, 68.6 to 80.1 percent) at the time of the last follow-up visit. Among the patients who completed the 12 weeks of treatment, the overall rates of response were 52 percent in the psychotherapy group (95 percent confidence interval, 44.6 to 59.6 percent), 55 percent in the nefazodone group (95 percent confidence interval, 47.5 to 62.6 percent), and 85 percent in the combined-treatment group (95 percent confidence interval, 79.7 to 90.2 percent). In both samples of patients, significantly more patients had a remission during combined treatment than during treatment with nefazodone or psychotherapy alone $(\mathrm{P}<0.001$ for all comparisons) (Table $3)$. In the modified intention-to-treat sample, the remission rates were 33 percent in the psychotherapy group, 29 percent in the nefazodone group, and 48 percent in the combined-treatment group. The respective rates of remission among the patients who completed the study were 24 percent, 22 percent, and 42 percent.

An analysis of covariance revealed significant differences between treatment groups with respect to the final HRSD scores for both the modified intention-totreat sample (Table 4) and in the patients who completed the study, with combined treatment more effective than either psychotherapy alone or nefazodone alone ( $\mathrm{P}<0.001$ for all comparisons). To examine the size of the differences between combined treatment and treatment with nefazodone or psychotherapy alone, we calculated effect sizes using Cohen's d (the difference between adjusted means divided by the pooled standard deviation). The effect sizes calculated for the group of patients who completed the study and for the modified intention-to-treat sample ranged from 0.54 to 0.64 for the comparison of combined treatment with the other two groups. There were no significant differences at end point between the nefazodone group and the psychotherapy group.

\section{Rates of Discontinuation and Adverse Events}

The rates of discontinuation were similar in the three groups $(\mathrm{P}=0.46)$ (Table 1$)$, with 24 percent of

Table 4. Mean Scores on the Hamilton Rating Scale for Depression at Base Line, Week 12, and the Last Follow-up Visit.*

\begin{tabular}{|c|c|c|c|c|}
\hline VARIABLE & $\begin{array}{l}\text { No. of } \\
\text { Patients }\end{array}$ & BASE LINE & WeEk 12 & $\begin{array}{c}\text { LAST FoLLOW-UP } \\
\text { VISIT }\end{array}$ \\
\hline \multicolumn{5}{|l|}{ Score } \\
\hline Nefazodone & 220 & $26.8 \pm 0.32$ & $14.7 \pm 0.70 \dagger$ & $15.8 \pm 0.64 \dagger$ \\
\hline Psychotherapy & 216 & $26.4 \pm 0.33$ & $15.1 \pm 0.69 \dagger$ & $16.0 \pm 0.63 \dagger$ \\
\hline Nefazodone and psychotherapy & 226 & $27.4 \pm 0.32$ & $9.7 \pm 0.65 \dagger$ & $10.8 \pm 0.63 \dagger$ \\
\hline \multicolumn{5}{|l|}{$P$ value for comparison between groups } \\
\hline Nefazodone vs. psychotherapy & & & 0.68 & 0.79 \\
\hline Nefazodone vs. combined treatment & & & $<0.001$ & $<0.001$ \\
\hline Psychotherapy vs. combined treatment & & & $<0.001$ & $<0.001$ \\
\hline \multicolumn{5}{|l|}{$\begin{array}{l}\text { Effect sizes (Cohen's d) for pairwise } \\
\text { comparisons } \ddagger\end{array}$} \\
\hline Nefazodone vs. psychotherapy & & & -0.05 & -0.02 \\
\hline Nefazodone vs. combined treatment & & & 0.59 & 0.54 \\
\hline Psychotherapy vs. combined treatment & & & 0.64 & 0.56 \\
\hline
\end{tabular}

*Plus-minus values are means \pm SE. Higher scores on the 24 -item test indicate more severe depression. Values for week 12 represent data from patients who completed the study, whereas values for the last follow-up visit represent data from the modified intention-to-treat sample.

$\dagger \mathrm{P}<0.001$ for the comparison with base-line score by the paired $t$-test.

$\ddagger$ The effect sizes were calculated as the difference between the adjusted means divided by the pooled standard deviation. 
all patients not completing the 12 -week study. The percentage of patients who dropped out because of lack of efficacy was low (1 percent in each group). The rate of discontinuation due to adverse events was 14 percent in the nefazodone group, 7 percent in the combined-treatment group, and 1 percent in the psychotherapy group. The most common reason for discontinuing psychotherapy was withdrawal of consent (in 14 percent of patients). Of the 32 patients who withdrew their consent, 5 did not want psychotherapy, 11 thought treatment was too time consuming, and 4 wanted medication. Seventy-two percent of the patients in the psychotherapy group who withdrew their consent did so within the first four weeks of treatment.

Table 5 lists the adverse events (whether or not they were thought to be related to treatment) that occurred in at least 10 percent of all patients. The adverse events in the groups receiving nefazodone were consistent with the known side effects of the medication, with headache, somnolence, dry mouth, nausea, and dizziness being the most common. Weight gain was rare, with no instances in the nefazodone or psychotherapy group and an incidence of 3.1 per-

Table 5. Common Adverse Events. *

\begin{tabular}{|c|c|c|c|c|}
\hline Adverse Event & $\begin{array}{l}\text { NEFAZODONE } \\
(\mathrm{N}=\mathbf{2 2 5})\end{array}$ & $\begin{array}{c}\text { PSYCHO- } \\
\text { THERAPY } \\
\text { ( } \mathbf{N}=\mathbf{2 2 1}) \\
\text { percent }\end{array}$ & $\begin{array}{c}\text { NEFAZODONE } \\
\text { AND PSYCHO- } \\
\text { THERAPY } \\
\text { (N=226) }\end{array}$ & $\begin{array}{c}\mathbf{P} \\
\text { VALUet }\end{array}$ \\
\hline Headache & 56 & 45 & 65 & $<0.001$ \\
\hline Asthenia & 17 & 6 & 20 & $<0.001$ \\
\hline Pain & 14 & 12 & 21 & 0.02 \\
\hline Abdominal pain & 13 & 10 & 18 & 0.08 \\
\hline Infection & 9 & 13 & 12 & 0.50 \\
\hline Back pain & 8 & 10 & 12 & 0.23 \\
\hline Dry mouth & 39 & 0 & 35 & $<0.001$ \\
\hline Nausea & 30 & 6 & 36 & $<0.001$ \\
\hline Dyspepsia & 21 & 12 & 19 & 0.02 \\
\hline Diarrhea & 19 & 10 & 23 & $<0.001$ \\
\hline Constipation & 16 & 1 & 17 & $<0.001$ \\
\hline Somnolence & 40 & 1 & 36 & $<0.001$ \\
\hline Dizziness & 25 & 2 & 29 & $<0.001$ \\
\hline Insomnia & 19 & 8 & 19 & 0.004 \\
\hline Lightheadedness & 12 & $<1$ & 14 & $<0.001$ \\
\hline Agitation & 10 & 2 & 8 & $<0.001$ \\
\hline Difficulty concentrating & 9 & 1 & 10 & $<0.001$ \\
\hline Pharyngitis & 12 & 5 & 10 & 0.05 \\
\hline Sinusitis & 12 & 11 & 10 & 0.89 \\
\hline Abnormal vision & 15 & $<1$ & 20 & $<0.001$ \\
\hline Blurred vision & 11 & 1 & 10 & $<0.001$ \\
\hline
\end{tabular}

*Adverse events that were reported by at least 10 percent of all patients are listed.

†Fisher's exact test was used to test for differences among the three groups. cent in the combined-treatment group. Sexual dysfunction (including impotence, psychosexual dysfunction, anorgasmia, and abnormal ejaculation) occurred in 3.5 percent of the patients in the nefazodone group, none of the patients in the psychotherapy group, and 3.5 percent of the patients in the combinedtreatment group.

\section{DISCUSSION}

We found that treatment with a combination of nefazodone and psychotherapy had significant advantages over treatment with nefazodone or psychotherapy alone. Despite the fact that the patients had had active depression for many years and that many had other psychiatric disorders as well, among the patients who completed the study, 85 percent of the patients in the combined-treatment group had a response to treatment by week 12 , as compared with 55 percent of patients in the nefazodone group and 52 percent of patients in the psychotherapy group. The rates of response and remission in the combined-treatment group were substantially higher than those that might have been anticipated on the basis of the outcomes of previous trials in similar patients. By contrast, in the modified intention-to-treat sample, the rate of response of 48 percent in both the nefazodone group and the psychotherapy group was similar to the rates reported for treatment with sertraline ( 52 percent), ${ }_{13}^{13}$ imipramine ( 51 percent) ${ }^{13}$ and desipramine $(51 \text { percent })^{18}$ in other studies of patients with chronic depression. The degree of superiority of combination therapy over monotherapy, as indicated by differences in the response rates and the sizes of the effects, suggests that combined treatment provides a clinically meaningful advantage. These results support previous recommendations, ${ }^{21}$ based on clinical experience, for the use of both psychotherapy and medication to treat patients with chronic depression.

Nefazodone produced effects more rapidly than did psychotherapy, with significant advantages evident in the first four weeks, whereas psychotherapy had a greater effect during the second part of the trial. By week 12 , the efficacy of the two approaches was similar. Although patients who were receiving nefazodone had higher frequencies of adverse events than those receiving psychotherapy, the rates of withdrawal from the study were similar in all three treatment groups. The fact that the efficacy of combined treatment and nefazodone was similar during the first four weeks of the study but that combined treatment was more efficacious later in the study suggests that when medication and psychotherapy are administered together, they continue to have independent rather than synergistic mechanisms of action.

A limitation of our study was the lack of a placebo control. However, a placebo-controlled study of patients with either a chronic major depressive disorder 
alone or a major depressive disorder plus dysthymia reported a relatively low rate of response to placebo (12 percent). ${ }^{14}$ In a study on the treatment of chronic forms of depression, the use of a placebo control would most likely greatly decrease the number of patients willing to participate, thereby reducing the generalizability of the findings. ${ }^{38}$

Another limitation, common to all studies of psychotherapy, was our inability to mask patients and therapists in the psychotherapy groups. To counteract this limitation, we had persons who were unaware of the patients' treatment assignments administer the HRSD. However, the clinicians were obviously not unaware of the treatment that patients were receiving.

Further limitations of our study include the restrictive exclusion criteria, which also reduced the generalizability of the findings, and the rates of withdrawal in conjunction with the lack of further data on patients after they withdrew. The slightly lower rate of withdrawal in the combined-treatment group (21 percent) than in the nefazodone group (26 percent) or the psychotherapy group ( 24 percent) may have biased the outcome comparisons.

In summary, we found that the combination of pharmacotherapy (nefazodone) and the cognitive behavioral-analysis system of psychotherapy was significantly more efficacious than either treatment alone for outpatients with chronic forms of depression. The rates of response to either treatment alone were similar and were also similar to the rates reported in previous trials of antidepressants for the treatment of chronic forms of depression in outpatients, indicating that at least one form of psychotherapy is effective in treating such patients. Although similarly effective, nefazodone produced effects more rapidly than did psychotherapy.

Supported by Bristol-Myers Squibb.

We are indebted to Drs. Jack E. Carr, Pedro L. Delgado, Frank Dowling, Gregory Eaves, Robert H. Howland, and Carina Vocisano for assisting with the study.

Editor's note: Our policy requires authors of Original Articles to disclose all financial ties with companies that make the products under study or competing products. In this case, the large number of authors and their varied and extensive financial associations with relevant companies make a detailed listing here impractical. Readers should know, however, that all but 1 (B.A.) of the 12 principal authors have had financial associations with Bristol-Myers Squibb - which also sponsored the study — and, in most cases, with many other companies producing psychoactive pharmaceutical agents. The associations include consultancies, receipt of research grants and honorariums, and participation on advisory boards. Of the 17 other authors, 2 are employees of Bristol-Myers Squibb, 5 (L.M.K., G.K., I.M., R.M., D.V.) have no relevant additional financial ties, and the others have a variety of associations similar to those just mentioned. Details are included as part of the article on the Journal's Web site (www.nejm.org) and are also available (as document no. 05552) from the National Auxiliary Publications Service, c/o Microfiche Publications, 248 Hempstead Tpk., West Hempstead, NY 11552.

\section{REFERENCES}

1. Judd LL, Akiskal HS, Paulus MP. The role and clinical significance of subsyndromal depressive symptoms (SSD) in unipolar major depressive disorder. J Affect Disord 1997;45:5-18.

2. Keller MB, Hanks DL, Klein DN. Summary of the DSM-IV mood disorders field trial and issue overview. Psychiatr Clin North Am 1996;19: $1-28$

3. Kocsis JH, Klein DN, eds. Diagnosis and treatment of chronic depression. New York: Guilford Press, 1995.

4. Kessler RC, McGonagle KA, Zhao S, et al. Lifetime and 12-month prevalence of DSM-III-R psychiatric disorders in the United States: results from the National Comorbidity Survey. Arch Gen Psychiatry 1994;51:819.

5. Weissman MM, Leaf PJ, Bruce ML, Florio L. The epidemiology of dys thymia in five communities: rates, risks, comorbidity, and treatment. Am J Psychiatry 1988;145:815-9.

6. Wells KB, Burnam MA, Rogers W, Hays R, Camp P. The course of depression in adult outpatients: results from the Medical Outcomes Study. Arch Gen Psychiatry 1992;49:788-94.

7. Hays RD, Wells KB, Sherbourne CD, Rogers W, Spritzer K. Functioning and well-being outcomes of patients with depression compared with chronic general medical illnesses. Arch Gen Psychiatry 1995;52:11-9.

8. Miller IW, Keitner GI, Schatzberg AF, et al. The treatment of chronic depression. 3. Psychosocial functioning before and after treatment with sertraline or imipramine. J Clin Psychiatry 1998;59:608-19.

9. Howland RH. Chronic depression. Hosp Community Psychiatry 1993; 44:633-9.

10. Klein DN, Norden KA, Ferro T, et al. Thirty-month naturalistic follow-up study of early-onset dysthymic disorder: course, diagnostic stability, and prediction of outcome. J Abnorm Psychol 1998;107:338-48.

11. Cassano GB, Akiskal HS, Perugi G, Musetti L, Savino M. The importance of measures of affective temperaments in genetic studies of mood disorders. J Psychiatr Res 1992;26:257-68.

12. Greenberg PE, Stiglin LE, Finkelstein SN, Berndt ER. The economic burden of depression in 1990. J Clin Psychiatry 1993;54:405-18.

13. Keller MB, Gelenberg AJ, Hirschfeld RMA, et al. The treatment of chronic depression. 2. A double-blind, randomized trial of sertraline and imipramine. J Clin Psychiatry 1998;59:598-607.

14. Kocsis JH, Frances AJ, Voss CB, Mann JJ, Mason BJ, Sweeney J. Imipramine treatment for chronic depression. Arch Gen Psychiatry 1988;45: 253-7.

15. Harrison WM, Stewart JW. Pharmacotherapy of dysthymic disorder In: Kocsis JH, Klein DN, eds. Diagnosis and treatment of chronic depression. New York: Guilford Press, 1995:124-45.

16. Thase ME, Fava M, Halbreich U, et al. A placebo-controlled, randomized clinical trial comparing sertraline and imipramine for the treatment of dysthymia. Arch Gen Psychiatry 1996;53:777-84.

17. Keller MB, Kocsis JH, Thase ME, et al. Maintenance phase efficacy of sertraline for chronic depression: a randomized controlled trial. JAMA 1998;280:1665-72.

18. Kocsis JH, Friedman RA, Markowitz JC, et al. Maintenance therapy for chronic depression: a controlled clinical trial of desipramine. Arch Gen Psychiatry 1996;53:769-76.

19. Markowitz JC. Psychotherapy of dysthymia. Am J Psychiatry 1994; 151:1114-21.

20. American Psychiatric Association. Practice guidelines for major depressive disorder in adults. Am J Psychiatry 1993;150:Suppl:1-26.

21. Depression Guideline Panel. Depression in primary care. Vol. 2. Treatment of major depression. Clinical practice guideline, number 5. Rockville, Md.: Agency for Health Care Policy and Research. 1993. (AHCPR publication no. 93-0551.)

22. Rush AJ, Thase ME. Psychotherapies for depressive disorders. In: Maj M, Sartorius N, eds. World Psychiatric Association series on evidence and practice in psychiatry. Vol. 1. Depressive disorders. Chichester, England: John Wiley, 1999:161-206.

23. Roth A, Fonagy P. What works for whom? A critical review of psychotherapy research. New York: Guilford Press, 1996.

24. Conte HR, Plutchik R, Wild KV, Karasu TB. Combined psychotherapy and pharmacotherapy for depression: a systematic analysis of the evidence. Arch Gen Psychiatry 1986;43:471-9.

25. McCullough JP. Treatment for chronic depression: cognitive behavior al analysis system of psychotherapy. New York: Guilford Press, 2000.

26. Idem. Cognitive-behavioral analysis system of psychotherapy: an interactional treatment approach for dysthymic disorder. Psychiatry 1984;47: 234-50.

27. Garlow SJ, Owens MJ, Nemeroff CB. Nefazodone. In: Sadock BJ, Sadock VA, eds. Kaplan \& Sadock's comprehensive textbook of psychiatry. 7th ed. Vol. 2. Philadelphia: Lippincott Williams \& Wilkins, 2000:2412-9. 
28. Feiger AD, Bielski RJ, Bremner J, et al. Double-blind, placebo-substitution study of nefazodone in the prevention of relapse during continuation treatment of outpatients with major depression. Int Clin Psychophar macol 1999; 14:19-28.

29. McCullough JP. Psychotherapy for dysthymia: a naturalistic study of ten patients. J Nerv Ment Dis 1991;179:734-40.

30. Klerman GL, Weissman MM, Rounsaville BJ, Chevron ES. Interpersonal psychotherapy of depression. New York: Basic Books, 1984.

31. Beck AT, Rush AJ, Shaw BG, Emery G. Cognitive therapy of depression. New York: Guilford Press, 1979.

32. Lewinsohn PM. A behavioral approach to depression. In: Friedman RJ, Katz MM, eds. The psychology of depression: contemporary theory and research. Washington, D.C.: Hemisphere Publishing, 1974:157-78.

33. Diagnostic and statistical manual of mental disorders, 4th ed.: DSM

IV. Washington, D.C.: American Psychiatric Association, 1994

34. First MB, Spitzer RL, Gibbon M, et al. Structured clinical interview for Axis-I DSM-IV disorders: patient edition (SCID-II, version 2.0). New York: New York State Psychiatric Institute Biometrics Research Department, 1994.

35. Hamilton M. Development of a rating scale for primary depressive illness. Br J Soc Clin Psychol 1967;6:278-96.

36. Fawcett J, Epstein P, Fiester SJ, Elkin I, Autry JH. Clinical management - imipramine/placebo administration manual: NIMH Treatment of Depression Collaboration Research Program. Psychopharmacol Bull 1987; 23:309-24.

37. McCullough JP. Therapist manual for cognitive behavioral analysis system of psychotherapy. Richmond: Virginia Commonwealth University, 1995

38. Rush AJ, Koran LM, Miller MB, et al. The treatment of chronic depression. 1. Study design and rationale for evaluating the comparative efficacy of sertraline and imipramine as acute, crossover, continuation, and maintenance phase therapies. J Clin Psychiatry 1998;59:589-97. 